\title{
The future of health research in the UK
}

\author{
Stephen W Smye and David Wynick
}

\section{Stephen W Smye \\ MA MSc PhD FIPEM \\ Hon FRCP, Director \\ of Research and \\ Development, \\ Leeds Teaching \\ Hospitals NHS \\ Trust}

David Wynick

BSc MBBS MD PhD

FRCP, Professor of

Molecular

Medicine, School

of Medical

Sciences,

University of Bristol

Clin Med

2007;7:542-3

\section{Best research for best health}

The Department of Health (DH) research and development (R\&D) strategy, Best research for best health $(B R f B H)$, was launched in January 2006 with the goal to secure and encourage the pursuit of clinical (defined as near-patient and near-service) research. The strategy explicitly identifies health services research and clinical trials as priorities, since they offer the prospect of a more immediate impact on clinical care. ${ }^{1}$

$B R f B H$, reviewed by Tim Evans in an earlier editorial, ${ }^{2}$ was endorsed not only by ministers at the $\mathrm{DH}$, but by the whole government, and the vigour with which it has been implemented has been impressive. In essence, $B R f B H$ changes $D H$ R\&D from being a supportive funding stream (which covered mainly the NHS costs of hosting externally funded noncommercial activity and provided for some 'own account' R\&D), to a directed and commissioned R\&D programme with an explicit emphasis on research excellence. In recent months, several key aspects of $B R f B H$ have been implemented:

- The National Institute for Health Research (NIHR) has been established ${ }^{3}$ to manage DH R\&D funding and activity, with faculty membership to be in place during 2007.

- The NIHR is managing a series of initiatives described in $B R f B H$, including awarding biomedical research centre (BRC) status to 11 trust and university partnerships; applied programme grants; and the establishment of comprehensive local research networks as part of the UK Clinical Research Network programme. ${ }^{4}$ Research and development support funding to all trusts in England will be reduced by $10 \%$ in $2007-8$, in order to fund the new arrangements.

- The BRC competition was a prominent feature of $B R f B H$ and awards were made in $2006 .^{3} \mathrm{~A}$ central element in the designation of BRCs was the University of Leiden's analysis of the contribution of NHS and higher education institutions to the world's top 20\% most highly cited publications (HCPs) within fields. While somewhat dated (the period covered was 1995 to 2000) and rather broad-brushed, the analysis does give an indication of the capacity for research excellence in England. It is notable that the comprehensive designated BRCs accounted for $48 \%$ of HCPs within leading NHS institutions and 55\% within leading universities. Therefore approximately half of England's capacity for excellent biomedical and translational research is supported (at least in part) by the current designations. The engagement of the remaining clinical centres in the delivery of world-class research remains a worthy goal, not least as significant patient flows are linked to non-BRC institutions. The recent call for NIHR Biomedical Research Units is very helpful in this regard.

As with all major changes, destabilisation of a stretched health service is probably the greatest immediate risk posed by $B R f B H$; for example, trusts which host some of the BRCs still stand to lose a significant amount of funding under the new arrangements, as do those, mainly provincial, major trusts which have not gained centre status. The recent announcement that in 2007-8 trusts will only see a $10 \%$ reduction in existing $\mathrm{R} \& \mathrm{D}$ funding mitigates the risk of destabilisation, at least in the short-term and, of course, all trusts can bid for the programmes and project schemes which form the core of $B R f B H$.

\section{The Cooksey review}

In 2006, the Cooksey review ${ }^{5}$ generally endorsed the approach introduced in $B R f B H$ and provided an authoritative overview of the history and context of the funding for health research in the UK while charting a course for the future that seeks to increase inward investment in R\&D and support a researchdriven healthcare system. An excellent critique of the Cooksey review has been written by Nick Black. ${ }^{6}$ Key recommendations of the review include the following:

- An Office for Strategic Coordination of Health

Research (OSCHR) should be created to set and monitor the delivery of the government's health research strategy, including the distribution of the research budget between NIHR and the Medical Research Council (MRC).

- The MRC should retain its current institutional structure and remain part of the Research Councils UK, but MRC boards will become 
more streamlined and representative of the broad spectrum of health research.

- The NIHR should become a real, rather than a virtual, institute, established as an executive agency of the $\mathrm{DH}$ by April 2009, when the reforms set out in the $B R f B H$ will have been fully implemented.

- Translational research should be a joint MRC-NIHR responsibility, with strategy overseen by a new translational medicine funding board and joint working facilitated by the OSCHR, with MRC technology continuing to play a key role.

- OSCHR will be responsible for communicating the UK's health priorities and to improve market signalling to the pharmaceuticals and biosciences sectors. OSCHR will 'brand' research projects, whether in the public or private sector, that it believes could address an unmet health need in the UK as 'UK priority health research projects' and develop a fasttrack drug development and approval process.

- The review also found that the NHS needs a stronger culture of research support. The review welcomed the announcement in the 2006 that the DH R\&D budget will be ring-fenced and emphasised the need to expand the Health Technology Assessment programme. A DH R\&D capital programme was also recommended.

The review carefully considered the future training of clinical academics and recommended that the component of the Medical Postgraduate Education and Training (MPET) budget used to support the training of clinical academic staff should be transferred to the DH R\&D budget, ring-fenced, and used specifically for this purpose. The review also identified the crucial role played in the UK of the relatively few medical doctors who also hold a $\mathrm{PhD}$ qualification and suggested that a further 50 applied fellowships per year may be needed to support the Walport Academic Clinical Fellows. The report also recommended the provision of competitively awarded Clinician Scientist Awards for the postdoctoral training of clinical lecturers and advised the transfer of this funding from MPET to the DH R\&D budget where it will also be ring-fenced. ${ }^{5}$ This element of the Cooksey review is particularly welcomed and represents further recognition of the need to support and develop academic medicine in a systematic and sustained manner.

Given the leading role that the medical profession will need to take in delivering translational clinical research, the need for a scientifically literate and research-active medical workforce is clear. It is essential that other national initiatives, particularly Modernising Medical Careers, emphasise the importance of scholarly and academic skills of trainee doctors.

\section{Conclusions}

The Cooksey review and $B R f B H$ reflect a welcome government commitment to health research, which aims to deliver research excellence, clinical innovation and a strong partnership with the major pharmaceutical and devices companies, and thereby encourage continued investment in the UK. The shape and direction of both reflect some political imperatives, but this is to be expected given the increasing accountability demanded by many. There are attendant risks that research priorities are set by political expedients rather than longer-term perspectives, but the new arrangements do appear to reduce the risk of the major budget reductions or misdirections that characterised earlier NHS R\&D arrangements. A recent editorial expressed real concern that translational research would be funded at the expense of basic biomedical research. ${ }^{7}$ Clinical researchers are well aware of the need to ensure that in the UK this is not simply protected, but is encouraged vigorously. Clinicians need to work with scientists to ensure that basic and translational research remain closely linked in practice, and that both areas are well funded. Over the next few years, the success of the Cooksey review and $B R f B H$ might be gauged in relation to the following questions:

- Is the new balance between basic and applied medical research appropriate, or will the pendulum have swung too far in favour of later stage clinical studies?

- Are the recommendations regarding the future MRC portfolio, direction and representation appropriate, and most importantly will the Haldane principal of independence from political inference be retained?

- Will the new arrangements encourage world-class R\&D which drives better clinical outcomes in the NHS?

- Will the pharmaceutical and major device industry have sufficient confidence in $B R f B H$ and the Cooksey review to look favourably on the UK and the NHS as an attractive host for their future R\&D studies?

- Do the Cooksey review and BRfBH sufficiently support academic medicine so that future clinical academics will find the arrangements for training and career developments sufficiently attractive to make academia a career choice?

If the answers to these questions are positive, then the strategy set out in the Cooksey review and Best research for best health will have been proved.

\section{References}

1 Department of Health. Best research for best health: a new national health research strategy. The NHS contribution to health research in England. London: DH, 2006.

2 Evans TW. Best research for best health: a new national health research strategy. Clin Med 2006;6:435-7.

3 National Institute for Health Research. www.nihr.ac.uk

4 UK Clinical Research Network. www.ukcrn.org.uk

5 Cooksey D. A review of UK health research funding. London: Stationery Office, 2006. www.hm-treasury.gov.uk

6 Black N. The Cooksey review of UK health research funding. BMJ 2006;333:1231-2.

7 Safe in their hands? Nature 2007;446:469. 